\title{
A general method of detecting additive, dominance and epistatic variation for metrical traits. V. Triple test cross analysis of disomically inherited traits expressed in triploid tissues
}

\author{
H. S. POONI*, ISH KUMAR† \& G. S. KHUSH $\ddagger$ \\ School of Biological Sciences, University of Birmingham, Edgbaston, Birmingham B15 2TT, U.K. †ProAgro, Hyderabad, \\ India and $\ddagger$ Department of Plant Breeding, IRRI, Philippines
}

\begin{abstract}
The applicability of the triple test cross design to the genetic analysis of metrical traits that subscribe to disomic inheritance but are expressed in a trisomic state has been investigated both theoretically and experimentally. Theory has shown that the standard sets of triple test cross families $\left(\mathrm{L}_{1 i}\right.$ etc.) do not provide unambiguous tests of the additive, dominance and epistatic effects when reciprocal crosses are analysed separately. Analysis of the backcross families also suffers from similar problems but only in respect of the additive component and the tests of dominance and epistasis are not biased by the parentage of the families. Selfs of the standard families, on the other hand, do not display reciprocal differences (of heritable kind) and therefore provide umambiguous tests of the additive, dominance and epistatic effects, but the dominance component is now detected with reduced reliability as the level of heterozygosity is halved due to selfing. Theory further shows that biases of the various tests are eliminated rather easily by including the reciprocal families in the analysis. This is confirmed to a large extent by the analysis of amylose content in rice which also reveals that it is controlled by genes that display both interallelic (additive and dominance) and nonallelic interactions. Furthermore, dominance is shown to be partial but the dominance ratio seems to be high for both the $h_{\mathrm{a} 1}$ and $h_{\mathrm{a} 2}$ types of non-additive effects.
\end{abstract}

Keywords: amylose, endosperm traits, gene action, rice, triploid tissues, TTC.

\section{Introduction}

The triple test cross breeding programme (TTC), a multiple mating scheme proposed by Kearsey \& Jinks (1968), is theoretically the best design for detecting and estimating the additive, dominance and epistatic components of variation for a quantitative trait. This design is so versatile that it can be applied to any population regardless of its gene and genotype frequencies (Jinks et al. 1969). Several of its modifications, such as those described by Jinks et al. (1969), Jinks \& Perkins (1970), Snape et al. (1975) and Pooni et al. (1980), are also known to be efficient designs that can be employed to study populations other than those produced by crossing a random sample of individuals with the three testers. These designs are, however, developed specifically for analysing those characters

\footnotetext{
${ }^{*}$ Correspondence.
}

that are disomically inherited/expressed and the present paper investigates their applicability to those traits that, despite being disomically inherited, are expressed in a trisomic phase.

\section{Theory}

\section{$F_{2}$ triple test cross}

An $F_{2}$ triple test cross involves crossing a random sample of $\mathrm{F}_{2}$ individuals (say $n$ ) with the two inbred parents and the $F_{1}$. The crossing programme (hereafter called the standard TTC) yields $3 n$ families that are cross-classified into $\mathrm{L}_{1 i}\left(\mathrm{~F}_{2 i} \times \mathrm{P}_{1}\right), \mathrm{L}_{2 i}\left(\mathrm{~F}_{2 i} \times \mathrm{P}_{2}\right)$ and $\mathrm{L}_{3 i}$ $\left(\mathrm{F}_{2 i} \times \mathrm{F}_{1}\right)$ groups and the variances of the orthogonal comparisons $\mathrm{L}_{1 i}+\mathrm{L}_{2 i}, \mathrm{~L}_{1 i}-\mathrm{L}_{2 i}$ and $\mathrm{L}_{1 i}+\mathrm{L}_{2 i}-2 \mathrm{~L}_{3 i}$ provide tests and estimates of the additive, dominance and epistatic components of genetic variation, respectively. Furthermore, while the crosses are usually made 
on the $F_{2}$ individuals (whenever possible) to avoid canalization and to minimize maternal interactions, there are however no constraints on the use of testers as mothers because they are also expected to yield identical results.

In the present case, however, the maternal genotype can affect the genotype of the progeny (see Pooni et al., 1992) and therefore we have to consider both the $F_{2}$ and the testers as maternal parents. Expectations of the various groups of families for these two situations are given in Table 1 for a single locus $A / a$ where the gene effects have been defined following Gale (1976).

It is apparent that the standard comparisons of the TTC analysis do not provide unbiased tests of the additive, dominance and epistatic variation when only a single set of reciprocal crosses $\left(\mathrm{L}_{1}, \mathrm{~L}_{2 i}\right.$ and $\left.\mathrm{L}_{3 i}\right)$ is considered. Instead of being $\frac{1}{8} d_{\mathrm{a}}^{2}$, the $\sigma^{2}$ from the $\mathrm{L}_{1 i}+\mathrm{L}_{2 i}$ comparison is now equal to $\frac{1}{8}\left(d_{\mathrm{a}}+\frac{1}{2} h_{\mathrm{a} 3}-\frac{1}{2} h_{\mathrm{a} 2}\right)^{2}$ for $\mathrm{F}_{2}$ females and $\frac{1}{8}\left(d_{\mathrm{a}}-\frac{1}{2} h_{\mathrm{a} 1}+\frac{1}{2} h_{\mathrm{a} 2}\right)^{2}$ when the testers are used as mothers (see Pooni et al., 1992 for symbols and definitions). Similarly, the expectation of $\sigma^{2}\left(\frac{1}{2} \mathrm{~L}_{1 i}-\frac{1}{2} \mathrm{~L}_{2 i}\right)$ is modified from $\frac{1}{8}\left(\frac{1}{2} h_{\mathrm{a} 1}+\frac{1}{2} h_{\mathrm{a} 2}\right)^{2}$ to $\frac{1}{144} d_{\mathrm{a}}^{2}+\frac{1}{8}\left(\frac{1}{2} h_{\mathrm{a} 1}+\frac{1}{2} h_{\mathrm{a} 2}\right)^{2}$ and of the epistatic comparison $\left(\mathrm{L}_{1 i}+\mathrm{L}_{2 i}-2 \mathrm{~L}_{3 i}\right)$ from zero to $\frac{1}{324} d_{\mathrm{a}}^{2}$. These expectations also apply to both types of female parents and therefore the tests of dominance and epistasis are not expected to differ between the mothers. Expectations of the alternative comparisons $\left(\mathrm{L}_{3 i}\right.$ and $\left.\mathrm{L}_{1 i}+\mathrm{L}_{2 i}+\mathrm{L}_{3 i}\right)$ that are often used to estimate the additive genetic variance (see Jinks and Perkins, 1970; Pooni \& Jinks, 1979) are also affected in the same manner. The between families component of the $\mathrm{L}_{3}$ generation has the expectation of $\frac{1}{2}\left(\frac{2}{3} d_{\mathrm{a}}+\frac{1}{4} h_{\mathrm{a} 1}-\frac{1}{4} h_{\mathrm{a} 2}\right)^{2}$ when the $\mathrm{F}_{2}$ are used as mothers and it is equal to $\frac{1}{2}\left(\frac{1}{3} d_{\mathrm{a}}-\frac{1}{4} h_{\mathrm{a} 1}+\frac{1}{4} h_{\mathrm{a} 2}\right)^{2}$ when the testers are used as females in the crossing programme. Similarly, the true variance of $\frac{1}{3}\left(\mathrm{~L}_{1 i}+\mathrm{L}_{2 i}+\mathrm{L}_{3 i}\right)$ has the expectation of $\frac{1}{2}\left(\frac{5}{9} d_{\mathrm{a}}+\frac{1}{4} h_{\mathrm{a} 1}-\frac{1}{4} h_{\mathrm{a} 2}\right)^{2}$ for the $\mathrm{F}_{2}$ mothers and $\frac{1}{2}\left(\frac{4}{9} d_{\mathrm{a}}-\frac{1}{4} h_{\mathrm{a} 1}+\frac{1}{4} h_{\mathrm{a} 2}\right)^{2}$ where testers are used as mothers.

All of these biases, however, cancel out when the scores of $\mathrm{L}_{1 i}, \mathrm{~L}_{2 i}$ and $\mathrm{L}_{3 i}$ are averaged over reciprocals. In these circumstances, $\sigma^{2}\left(\mathrm{~L}_{1 i}+\mathrm{L}_{2 i}\right)=\frac{1}{8} d_{\mathrm{a}}^{2}$, $\sigma^{2}\left(\mathrm{~L}_{1 i}-\mathrm{L}_{2 i}\right)=\frac{1}{8}\left(\frac{1}{2} h_{\mathrm{a} 1}+\frac{1}{2} h_{\mathrm{a} 2}\right)^{2}$ and $\sigma^{2}\left(\mathrm{~L}_{1 i}+\mathrm{L}_{2 i}-2 \mathrm{~L}_{3 i}\right)$ $=0$ in the absence of epistasis. Expectations of these $\sigma^{2} \mathrm{~s}$ and of the three standard comparisons of the TTC that are based on the averages of reciprocals are given in Table 2.

Table 1 Expectations of the $\mathrm{L}_{1 i}, \mathrm{~L}_{2 i}$ and $\mathrm{L}_{3 i}$ families of a triple test cross where the $\mathrm{F}_{2}$ individuals and the testers are used as maternal parents $\dagger$

\begin{tabular}{lcccc}
\hline $\mathrm{F}_{2}$ sample & Frequency & $\mathrm{L}_{1 i}$ & $\mathrm{~L}_{2 i}$ & $\mathrm{~L}_{3 i}$ \\
\hline $\begin{array}{l}\mathrm{F}_{2} \text { individuals as females } \\
A A A\end{array}$ & $\frac{1}{4}$ & $d_{\mathrm{a}}$ & $h_{\mathrm{a} 1}$ & $\frac{2}{3} d_{\mathrm{a}}+\frac{1}{2} h_{\mathrm{a} 1}$ \\
$A A a$ & $\frac{1}{4}$ & $\frac{1}{3} d_{\mathrm{a}}+\frac{1}{2} h_{\mathrm{a} 2}$ & $-\frac{1}{3} d_{\mathrm{a}}+\frac{1}{2} h_{\mathrm{a} 1}$ & $\frac{1}{4} h_{\mathrm{a} 1}+\frac{1}{4} h_{\mathrm{a} 2}$ \\
$a a A$ & $\frac{1}{4}$ & $\frac{1}{3} d_{\mathrm{a}}+\frac{1}{2} h_{\mathrm{a} 2}$ & $-\frac{1}{3} d_{\mathrm{a}}+\frac{1}{2} h_{\mathrm{a} 1}$ & $\frac{1}{4} h_{\mathrm{a} 1}+\frac{1}{4} h_{\mathrm{a} 2}$ \\
$a a a$ & $\frac{1}{4}$ & $h_{\mathrm{a} 2}$ & $-d_{\mathrm{a}}$ & $-\frac{2}{3} d_{\mathrm{a}}+\frac{1}{2} h_{\mathrm{a} 2}$ \\
Testers as females & & & \\
$A A A$ & $\frac{1}{4}$ & $d_{\mathrm{a}}$ & $h_{\mathrm{a} 2}$ & $\frac{1}{3} d_{\mathrm{a}}+\frac{1}{2} h_{\mathrm{a} 2}$ \\
$A A a$ & $\frac{1}{4}$ & $\frac{2}{3} d_{\mathrm{a}}+\frac{1}{2} h_{\mathrm{a} 1}$ & $-\frac{2}{3} d_{\mathrm{a}}+\frac{1}{2} h_{\mathrm{a} 2}$ & $\frac{1}{4} h_{\mathrm{a} 1}+\frac{1}{4} h_{\mathrm{a} 2}$ \\
$a a A$ & $\frac{1}{4}$ & $\frac{2}{3} d_{\mathrm{a}}+\frac{1}{2} h_{\mathrm{a} 1}$ & $-\frac{2}{3} d_{\mathrm{a}}+\frac{1}{2} h_{\mathrm{a} 2}$ & $\frac{1}{4} h_{\mathrm{a} 1}+\frac{1}{4} h_{\mathrm{a} 2}$ \\
$a a a$ & $\frac{1}{4}$ & $h_{\mathrm{a} 1}$ & $-d_{\mathrm{a}}$ & $-\frac{1}{3} d_{\mathrm{a}}+\frac{1}{2} h_{\mathrm{a} 1}$ \\
\hline
\end{tabular}

$\dagger$ All expectations are given as deviations from ' $m$ '.

Table 2 Expectations of the $\mathrm{L}_{1 i}^{\prime}+\mathrm{L}_{2 i}^{\prime}, \mathrm{L}_{1 i}^{\prime}-\mathrm{L}_{2 i}^{\prime}$ and $\mathrm{L}_{1 i}^{\prime}+\mathrm{L}_{2 i}^{\prime}-2 \mathrm{~L}_{3 i}^{\prime}$ comparisons where $\mathrm{L}_{l}^{\prime}, \mathrm{L}_{2 i}^{\prime}$ and $\mathbf{L}_{3 i}^{\prime}$ represent sums of reciprocals

\begin{tabular}{lcccc}
\hline $\mathrm{F}_{2}$ sample & Frequency & $\mathrm{L}_{1 i}^{\prime}+\mathrm{L}_{2 i}^{\prime}$ & $\mathrm{L}_{1 i}^{\prime}-\mathbf{L}_{2 i}^{\prime}$ & $\mathrm{L}_{1 i}^{\prime}+\mathrm{L}_{2 i}^{\prime}-2 \mathrm{~L}_{3 i}^{\prime}$ \\
\hline$A A A$ & $\frac{1}{4}$ & $2 d_{\mathrm{a}}+h_{\mathrm{a} 1}+h_{\mathrm{a} 2}$ & $2 d_{\mathrm{a}}-h_{\mathrm{a} 1}-h_{\mathrm{a} 2}$ & 0 \\
$A A a$ & $\frac{1}{4}$ & $h_{\mathrm{a} 1}+h_{\mathrm{a} 2}$ & $2 d_{\mathrm{a}}$ & 0 \\
$a a A$ & $\frac{1}{4}$ & $h_{\mathrm{a} 1}+h_{\mathrm{a} 2}$ & $2 d_{\mathrm{a}}$ & 0 \\
$a a a$ & $\frac{1}{4}$ & $-2 d_{\mathrm{a}}+h_{\mathrm{a} 1}+h_{\mathrm{a} 2}$ & $2 d_{\mathrm{a}}+h_{\mathrm{a} 1}+h_{\mathrm{a} 2}$ & 0 \\
& \multicolumn{3}{c}{$\sigma^{2}\left(\mathbf{L}_{1 i}^{\prime}+\mathrm{L}_{2 i}^{\prime}\right)=\frac{1}{8} d_{\mathrm{a}}^{2}$} \\
& $\sigma^{2}\left(\mathbf{L}_{1 i}^{\prime}-\mathrm{L}_{2 i}^{\prime}\right)=\frac{1}{8}\left(1 / 2 h_{\mathrm{a} 1}+1 / 2 h_{\mathrm{a} 2}\right)^{2}$ \\
\hline
\end{tabular}




\section{Selfed families}

When individual crosses yield one or few seeds, a practical alternative is to self the $\mathrm{L}_{1 i}, \mathrm{~L}_{2 i}$ and $\mathrm{L}_{3 i}$ families (Kearsey \& Jinks, 1968; Pooni et al., 1980). In the present case, one needs to self only one set of reciprocals as selfs of reciprocals are not expected to differ, except in the presence of interactions between the maternal and progeny genotypes. Furthermore, because most of the $\mathrm{L}_{1 i}, \mathrm{~L}_{2 i}$ and $\mathrm{L}_{3 i}$ families are expected to be genetically heterogeneous, particularly when many loci are segregating, random samples of individuals have to be selfed from each family and the triple test cross analysis carried out on the averaged scores of the selfed families $\left(\mathrm{L}_{1 s i}, \mathrm{~L}_{2 s i}\right.$ and $\mathrm{L}_{3 s i}$ etc.). Table 3 shows that the sums, differences and epistatic comparisons of these scores provide unbiased tests of the additive, dominance and epistatic effects irrespective of the maternal parentage of the crosses. The reduction of heterozygosity among the families, however, affects the efficiency of the test of dominance and consequently tests of the additive and dominance effects are now subjected to unequal precision.

$\mathrm{L}_{1 s i}+\mathrm{L}_{2 s i}+\mathrm{L}_{3 s i}$ and $\mathrm{L}_{3 s i}$ variances also provide unbiased tests of the additive genetic variance (in the absence of epistasis) and their $\sigma^{2}$ s have the expectation of $\frac{1}{8} d_{\mathrm{a}}^{2}$.

\section{Backcross families}

Where selfing is difficult and backcrossing is used routinely in the breeding programmes, TTC analysis can be based on the backcross families. Once again, backcrosses can be made using testers or the individ- uals of the $\mathrm{L}_{1 i}, \mathrm{~L}_{2 i}$ and $\mathrm{L}_{3 i}$ families as mothers. The expected scores of these families (Table 4) again show that some comparisons will provide biased tests of the gene effects and the biases will be much larger in magnitude than those incurred by the same comparisons of the $\mathrm{F}_{2}$ TTC described earlier. More precisely, $\mathrm{L}_{1 b i}+\mathrm{L}_{2 b i}$ is the only comparison whose $\sigma^{2}$ is biased and it has an expectation of $\frac{1}{2}\left(\frac{1}{3} d_{\mathrm{a}}+\frac{1}{4} h_{\mathrm{a} 1}-\frac{1}{4} h_{\mathrm{a} 2}\right)^{2}$, when testers are used as maternal parents. This expectation is modified to $\frac{1}{2}\left(\frac{1}{6} d_{\mathrm{a}}-\frac{1}{4} h_{\mathrm{a} 1}+\frac{1}{4} h_{\mathrm{a} 2}\right)^{2}$ when crosses are made on the individuals from the test cross families, and the analysis of the averages of reciprocals gives $\sigma^{2}\left(\mathrm{~L}_{1 b i}+\mathrm{L}_{2 b i}\right)=\frac{1}{32} d_{\mathrm{a}}^{2}$.

Expectations of the $\mathrm{L}_{1 b i}-\mathrm{L}_{2 b i}$ and $\mathrm{L}_{1 b i}+\mathrm{L}_{2 b i}-2 \mathrm{~L}_{3 b i}$ comparisons, on the other hand, are not affected by the maternal parents and their $\sigma^{2}$ s provide unbiased tests of dominance $\left[=\frac{1}{32}\left(\frac{1}{2} h_{\mathrm{a} 1}+\frac{1}{2} h_{\mathrm{a} 2}\right)^{2}\right]$ and epistasis, respectively. Further details of the expectations of these comparisons are given in Table 5.

Expectations of $\sigma^{2}\left(\mathrm{~L}_{3 \mathrm{~b} i}\right)$ and $\sigma^{2}\left(\mathrm{~L}_{1 \mathrm{~b} i}+\mathrm{L}_{2 \mathrm{~b} i}+\mathrm{L}_{3 \mathrm{~b} i}\right)$ also differ between reciprocals and both of these components provide estimates of $\frac{1}{2}\left(\frac{1}{3} d_{\mathrm{a}}+\frac{1}{8} h_{\mathrm{a} 1}-\frac{1}{8} h_{\mathrm{a} 2}\right)^{2}$ and $\frac{1}{2}\left(\frac{1}{6} d_{\mathrm{a}}-\frac{1}{8} h_{\mathrm{a} 1}+\frac{1}{8} h_{\mathrm{a} 2}\right)^{2}$ where test cross individuals and testers, respectively, are used as mothers.

\section{Inbred lines}

Use of $\mathrm{F}_{\infty}$ inbred $\left(\mathrm{P}_{i}\right)$ lines instead of $\mathrm{F}_{2}$ in a standard TTC generally increases the power of its tests. This is achieved at two levels. Firstly, the error mean square is reduced due to the elimination of genetic variation from the within variances of the $\mathrm{L}_{1 i}$ and $\mathrm{L}_{2 i}$ sets of families. Secondly, the various $\sigma^{2}$ s now account for

Table 3 Expectations of the $\mathrm{L}_{1 s i}, \mathrm{~L}_{2 s i}$ and $\mathrm{L}_{3 s i}$ families and of the corresponding sums, differences and epistatic comparisons

\begin{tabular}{|c|c|c|c|}
\hline$F_{2}$ sample & & est crosses/comparis & \\
\hline $\begin{array}{l}A A A \\
A A a \\
a a A \\
a a a\end{array}$ & $\begin{array}{c}\mathrm{L}_{1 \mathrm{~s} i} \\
d_{\mathrm{a}} \\
\frac{1}{2} d_{\mathrm{a}}+\frac{1}{8} h_{\mathrm{a} 1}+\frac{1}{8} h_{\mathrm{a} 2} \\
\frac{1}{2} d_{\mathrm{a}}+\frac{1}{8} h_{\mathrm{a} 1}+\frac{1}{8} h_{\mathrm{a} 2} \\
\frac{1}{4} h_{\mathrm{a} 1}+\frac{1}{4} h_{\mathrm{a} 2}\end{array}$ & $\begin{array}{c}\mathrm{L}_{2 s i} \\
\frac{1}{4} h_{\mathrm{a} 1}+\frac{1}{4} h_{\mathrm{a} 2} \\
-\frac{1}{2} d_{\mathrm{a}}+\frac{1}{8} h_{\mathrm{a} 1}+\frac{1}{8} h_{\mathrm{a} 2} \\
-\frac{1}{2} d_{\mathrm{a}}+\frac{1}{8} h_{\mathrm{a} 1}+\frac{1}{8} h_{\mathrm{a} 2} \\
-d_{\mathrm{a}}\end{array}$ & $\begin{array}{c}\mathrm{L}_{3 \mathrm{~s} i} \\
\frac{1}{2} d_{\mathrm{a}}+\frac{1}{8} h_{\mathrm{a} 1}+\frac{1}{8} h_{\mathrm{a} 2} \\
\frac{1}{8} h_{\mathrm{a} 1}+\frac{1}{8} h_{\mathrm{a} 2} \\
\frac{1}{8} h_{\mathrm{a} 1}+\frac{1}{8} h_{\mathrm{a} 2} \\
-\frac{1}{2} d_{\mathrm{a}}+\frac{1}{8} h_{\mathrm{a} 1}+\frac{1}{8} h_{\mathrm{a} 2}\end{array}$ \\
\hline $\begin{array}{l}A A A \\
A A a \\
a a A \\
a a a\end{array}$ & $\begin{array}{c}\mathrm{L}_{\mathrm{Isi}}+\mathrm{L}_{2 s i} \\
d_{\mathrm{a}}+\frac{1}{4} h_{\mathrm{a} 1}+\frac{1}{4} h_{\mathrm{a} 2} \\
\frac{1}{4} h_{\mathrm{a} 1}+\frac{1}{4} h_{\mathrm{a} 2} \\
\frac{1}{4} h_{\mathrm{a} 1}+\frac{1}{4} h_{\mathrm{a} 2} \\
-d_{\mathrm{a}}+\frac{1}{4} h_{\mathrm{a} 1}+\frac{1}{4} h_{\mathrm{a} 2}\end{array}$ & $\begin{array}{c}\mathrm{L}_{\mathrm{1si}}-\mathrm{L}_{2 s i} \\
\frac{1}{2} d_{\mathrm{a}}-\frac{1}{4} h_{\mathrm{a} 1}-\frac{1}{4} h_{\mathrm{a} 2} \\
\frac{1}{2} d_{\mathrm{a}} \\
\frac{1}{2} d_{\mathrm{a}} \\
\frac{1}{2} d_{\mathrm{a}}+\frac{1}{4} h_{\mathrm{a} 1}+\frac{1}{4} h_{\mathrm{a} 2} \\
2 \mathrm{si}\rangle=\frac{1}{8} d_{\mathrm{a}}^{2} \\
\frac{1}{2}\left(\frac{1}{2} h_{\mathrm{a} 1}+\frac{1}{2} h_{\mathrm{a} 2}\right)^{2}\end{array}$ & $\begin{array}{c}\mathrm{L}_{\mathrm{lsi} i}+\mathrm{L}_{2 s i}-2 \mathrm{~L}_{3 s i} \\
0 \\
0 \\
0 \\
0\end{array}$ \\
\hline
\end{tabular}

$\mathrm{s}$ stands for selfs of $\mathrm{L}_{1 i}$ etc. 
Table 4 Expectations of the $\mathrm{L}_{1 \mathrm{~h} i}, \mathrm{~L}_{2 \mathrm{~b} i}$ and $\mathrm{L}_{3 \mathrm{~b} i}$ families of a triple test cross where individuals of test crosses and the testers are used as maternal parents

\begin{tabular}{|c|c|c|c|c|}
\hline $\mathrm{F}_{2}$ & Frequency & $\mathrm{L}_{\mathrm{Ibi}}$ & $\mathrm{L}_{2 \mathrm{~b} i}$ & $\mathrm{~L}_{3 \mathrm{~b} i}$ \\
\hline \multicolumn{5}{|c|}{ Test cross individuals as females } \\
\hline$A A A$ & $\frac{1}{4}$ & $d_{\mathrm{a}}$ & $-\frac{1}{3} d_{\mathrm{a}}+\frac{1}{2} h_{\mathrm{al}}$ & $\frac{1}{3} d_{\mathrm{a} a}+\frac{3}{8} h_{\mathrm{a} 1}+\frac{1}{8} h_{\mathrm{a} 2}$ \\
\hline$A A a$ & $\frac{1}{4}$ & $\frac{2}{3} d_{\mathrm{a}}+\frac{1}{4} h_{\mathrm{a} 2}$ & $-\frac{2}{3} d_{\mathrm{a}}+\frac{1}{4} h_{\mathrm{a} 1}$ & $\frac{1}{4} h_{\mathrm{a} 1}+\frac{1}{4} h_{\mathrm{a} 2}$ \\
\hline$a a A$ & $\frac{1}{4}$ & $\frac{2}{3} d_{\mathrm{a}}+\frac{1}{4} h_{\mathrm{a} 2}$ & $-\frac{2}{3} d_{\mathrm{i}}+\frac{1}{4} h_{\mathrm{a} 1}$ & $\frac{1}{4} h_{\mathrm{a} 1}+\frac{1}{4} h_{\mathrm{a} 2}$ \\
\hline$a a a$ & $\frac{1}{4}$ & $\frac{1}{3} d_{\mathrm{a}}+\frac{1}{2} h_{\mathrm{a} 2}$ & $-d_{\mathrm{a}}$ & $-\frac{1}{3} d_{\mathrm{a}}+\frac{1}{8} h_{\mathrm{a} 1}+\frac{3}{8} h_{\mathrm{a} 2}$ \\
\hline \multicolumn{5}{|c|}{ Testers as females } \\
\hline$A A A$ & $\frac{1}{4}$ & $d_{\mathrm{a}}$ & $-\frac{2}{3} d_{\mathrm{a}}+\frac{1}{2} h_{\mathrm{a} 2}$ & $\frac{1}{6} d_{\mathrm{a}}+\frac{1}{8} h_{\mathrm{a} 1}+\frac{3}{8} h_{\mathrm{a} 2}$ \\
\hline$A A a$ & $\frac{1}{4}$ & $\frac{5}{6} d_{\mathrm{a}}+\frac{1}{4} h_{\mathrm{a} 1}$ & $-\frac{5}{5} d_{\mathrm{a}}^{a}+\frac{1}{4} h_{\mathrm{a} 2}$ & $\frac{1}{4} h_{\mathrm{a} 1}+\frac{1}{4} h_{\mathrm{a} 2}$ \\
\hline$a a A$ & $\frac{1}{4}$ & $\frac{5}{6} d_{\mathrm{a} a}+\frac{1}{4} h_{\mathrm{a} 1}$ & $-\frac{5}{6} d_{\mathrm{a}}+\frac{1}{4} h_{\mathrm{a} 2}$ & $\frac{1}{4} h_{\mathrm{a} 1}+\frac{1}{4} h_{\mathrm{a} 2}$ \\
\hline$a a a$ & $\frac{1}{4}$ & $\frac{2}{3} d_{\mathrm{a}}+\frac{1}{2} h_{\mathrm{al}}$ & $-d_{\mathrm{a}}$ & $-\frac{1}{6} d_{\mathrm{a}}+\frac{3}{8} h_{\mathrm{a} 1}+\frac{1}{8} h_{\mathrm{a} 2}$ \\
\hline
\end{tabular}

Table 5 Expectations of the $\mathrm{L}_{\mathrm{lb} i}^{\prime}+\mathrm{L}_{2 \mathrm{~b} i}^{\prime}, \mathrm{L}_{\mathrm{lb} i}^{\prime}-\mathrm{L}_{2 \mathrm{~b} i}^{\prime}$ and $\mathrm{L}_{1 \mathrm{~b} i}^{\prime}+\mathrm{L}_{2 \mathrm{~b} i}^{\prime}-2 \mathrm{~L}_{3 \mathrm{~b} i}^{\prime}$ comparisons where $\mathrm{L}_{\mathrm{bb} i}^{\prime}, \mathrm{L}_{2 \mathrm{~b} i}^{\prime}$ and $\mathrm{L}_{3 \mathrm{~b} i}^{\prime}$ represent sums of reciprocals

\begin{tabular}{|c|c|c|c|c|}
\hline $\mathrm{F}_{2}$ & Frequency & $\mathrm{L}_{1 \mathrm{bi} i}^{\prime}+\mathrm{L}_{2 \mathrm{~b} i}^{\prime}$ & $\mathrm{L}_{1 \mathrm{bi} i}^{\prime}-\mathrm{L}_{2 \mathrm{~b} i}^{\prime}$ & $\mathrm{L}_{1 \mathrm{~b} i}^{\prime}+\mathrm{L}_{2 \mathrm{~b} i}^{\prime}-2 \mathrm{~L}_{3 \mathrm{~b} i}^{\prime}$ \\
\hline $\begin{array}{l}A A A \\
A A a \\
a a A \\
a a a\end{array}$ & $\begin{array}{l}\frac{1}{4} \\
\frac{1}{4} \\
\frac{1}{4} \\
\frac{1}{4}\end{array}$ & $\begin{array}{r}d_{\mathrm{a}}+\frac{1}{2} h_{\mathrm{a} 1}+\frac{1}{2} h_{\mathrm{a} 2} \\
\frac{1}{2} h_{\mathrm{a} 1}+\frac{1}{2} h_{\mathrm{a} 2} \\
\frac{1}{2} h_{\mathrm{a} 1}+\frac{1}{2} h_{\mathrm{a} 2} \\
-d_{\mathrm{a}}+\frac{1}{2} h_{\mathrm{a} 1}+\frac{1}{2} h_{\mathrm{a} 2} \\
\sigma^{2}\left(\mathrm{~L}_{1}^{\prime}\right. \\
\sigma^{2}\left(\mathrm{~L}_{\mathrm{jb} i}^{\prime}-\mathrm{L}\right.\end{array}$ & $\begin{array}{c}3 d_{\mathrm{a}}-\frac{1}{2} h_{\mathrm{a} 1}-\frac{1}{2} h_{\mathrm{a} 2} \\
3 d_{\mathrm{a}} \\
3 d_{\mathrm{a}} \\
3 d_{\mathrm{a}}+\frac{1}{2} h_{\mathrm{a} 1}+\frac{1}{2} h_{\mathrm{a} 2} \\
\left.{ }_{2}\right)^{2}\end{array}$ & $\begin{array}{l}-\frac{1}{4} h_{\mathrm{a} 1}-\frac{1}{4} h_{\mathrm{a} 2} \\
-\frac{1}{4} h_{\mathrm{a} 1}-\frac{1}{4} h_{\mathrm{a} 2} \\
-\frac{1}{4} h_{\mathrm{a} 1}-\frac{1}{4} h_{\mathrm{a} 2} \\
-\frac{1}{4} h_{\mathrm{a} 1}-\frac{1}{4} h_{\mathrm{a} 2}\end{array}$ \\
\hline
\end{tabular}

larger fractions of genetic variation. For example, $\sigma^{2} \mathrm{~s}$ of the $\mathrm{L}_{1 i}+\mathrm{L}_{2 i}$ and $\mathrm{L}_{1 i}-\mathrm{L}_{2 i}$ comparisons provide estimates of $\frac{1}{4} d_{\mathrm{a}}^{2}$ and $\frac{1}{4}\left(\frac{1}{2} h_{\mathrm{a} 1}+\frac{1}{2} h_{\mathrm{a} 2}\right)^{2}$ compared with $\frac{1}{8} d_{\mathrm{a}}^{2}$ and $\frac{1}{8}\left(\frac{1}{2} h_{\mathrm{a} 1}+\frac{1}{2} h_{\mathrm{a} 2}\right)^{2}$, respectively, when the TTC involves $\mathrm{F}_{\infty}$ instead of $F_{2}$ genotypes.

The availability of inbred $\left(\mathrm{P}_{i}\right)$ scores also allows one to reduce the crossing programme by excluding $\mathrm{L}_{3 i}$ families and hasten the study by one generation because then there is no need to cross the testers (to obtain the $\mathrm{F}_{1}$ ) prior to producing the $\mathrm{L}_{1 i}, \mathrm{~L}_{2 i}$ and $\mathrm{L}_{3 i}$ sets of families. In these circumstances, the standard test of epistasis $\left(\mathrm{L}_{1 i}+\mathrm{L}_{2 i}-2 \mathrm{~L}_{3 i}=0\right)$ is replaced by the comparison $\mathrm{L}_{1 i}+\mathrm{L}_{2 i}-\mathrm{P}_{i}$, following Jinks et al. (1969).

Substitution of the $\mathrm{F}_{\infty}$ lines with a sample of inbreds of unknown origin, on the other hand, affects the expectations of various comparisons in such a way that $\sigma^{2}\left(\mathrm{~L}_{1 i}+\mathrm{L}_{2 i}\right)$ and $\sigma^{2}\left(\mathrm{~L}_{1 i}-\mathrm{L}_{2 i}\right)$ of a standard TTC provide estimates of $u v d_{\mathrm{a}}^{2}$ and $u v\left(\frac{1}{2} h_{\mathrm{a} 1}+\frac{1}{2} h_{\mathrm{a} 2}\right)^{2}$ instead of $\frac{1}{4} d_{\mathrm{a}}^{2}$ and $\frac{1}{4}\left(\frac{1}{2} h_{\mathrm{a} 1}+\frac{1}{2} h_{\mathrm{a} 2}\right)^{2}$, respectively, where $u$ and $v$ represent the frequencies of $A$ and $a$ alleles in the sample. These definitions also remain valid for the selfed and backcross families and many other situations provided the general conditions of no epistasis, genotype-environment interaction and linkage disequilibrium are met.

\section{Materials and analyses}

The material consisted of seven pure breeding lines of indica rice and their reciprocally produced $\mathrm{F}_{1}, \mathrm{~F}_{2}, \mathrm{~B}_{1}$ and $\mathrm{B}_{2}$ generations. The lines were selected on the basis of their amylose content and the basic generations derived from their pairwise crosses were produced during 1985 (dry season). Random samples of seed were then taken from each generation and their amylose content measured following Juliano (1971). Further details of the experiment and a summary of the generation means and variances is provided by Pooni et al. (1993b) who analysed the data from various generations as separate diallels.

To test for the additive and dominance effects we need only two arrays from the diallel. We can also analyse the reciprocals separately before subjecting them to a joint analysis. The arrays that we chose from the diallel are those of varieties IR 8 and IR29 which had the highest ( 27.26 per cent) and the lowest ( 0 per 
cent) amylose contents among the seven lines. These varieties were chosen to maximize genetic diversity in the testers and to avoid gene fixation which can affect the efficiency of the analysis adversely (Virk \& Jinks, 1977).

Furthermore, the analyses have been carried out assuming two sample sizes. In the first case, testers were considered to be part of the sample thus giving a TTC of $7 \times 5$ dimension, including reciprocals. This complicates the analysis, particularly the tests of epistasis and the calculation of the sum of squares (SS) for the combined analyses as reciprocal/independent scores are not available for the tester genotypes. Consequently, the presence of epistasis is determined from only five values of the $\mathrm{L}_{1 i}+\mathrm{L}_{2 i}-\mathrm{P}_{i}$ comparison and the SS of the sums and the differences comparisons are calculated assuming missing values.

The second analysis avoided the above problems as the testers were excluded from the sample and the TTC was reduced to $5 \times 3$ dimension, excluding reciprocals.

The main items of these analyses are tested against the interaction mean-squares (for 8 d.f.) that are calculated separately for the standard, selfed and backcross families from the SS pertaining to their sums and differences comparisons and are found significant throughout. These analyses are presented for the various sets of families in Tables 6-8 and the corresponding esti-

Table 6 Analyses of the $\mathrm{P}_{i}, \mathrm{~L}_{1 i}$ and $\mathrm{L}_{2 i}$ sets of families

\begin{tabular}{|c|c|c|c|c|c|c|}
\hline \multirow[b]{2}{*}{ Item } & \multicolumn{3}{|c|}{ With tester families } & \multicolumn{3}{|c|}{ Without tester families } \\
\hline & d.f. & MS & $P$ & d.f. & MS & $P$ \\
\hline \multicolumn{7}{|c|}{ Inbred lines as females } \\
\hline$†$ Epistasis & 4 & 3.43 & ns & 4 & 3.43 & ns \\
\hline Sums & 6 & 71.32 & $* * *$ & 4 & 47.27 & $* * *$ \\
\hline Differences & 6 & 48.56 & $* * *$ & 4 & 36.25 & $* * *$ \\
\hline \multicolumn{7}{|c|}{ Testers as females } \\
\hline Epistasis & 4 & 8.58 & * & 4 & 8.58 & $*$ \\
\hline Sums & 6 & 65.18 & $* * *$ & 4 & 62.36 & $* * *$ \\
\hline Differences & 6 & 49.42 & $* * *$ & 4 & 37.69 & $* * *$ \\
\hline \multicolumn{7}{|c|}{ Combined analysis } \\
\hline Epistasis & 4 & 5.85 & ns & 4 & 5.85 & ns \\
\hline Sums & 6 & 109.09 & $* * *$ & 4 & 107.37 & $* * *$ \\
\hline Differences & 6 & 97.07 & $* * *$ & 4 & 72.65 & $* * *$ \\
\hline Interaction & 8 & 1.93 & $* * *$ & 8 & 1.93 & $* * *$ \\
\hline Error & 931 & 0.12 & & 931 & 0.12 & \\
\hline
\end{tabular}

† See Table 2 for comparisons.

ns $P>0.05, * 0.05 \geqslant P>0.01,{ }^{* *} 0.01 \geqslant P>0.001$,

$* * * * \leq 0.001$. mates of the additive $\left(D^{\prime}=4 \Sigma u v d_{i}^{2}\right)$ and the dominance $\left[H^{\prime}=4 \Sigma u v\left(\frac{1}{2} h_{i 1}+\frac{1}{2} h_{i 2}\right)^{2}\right]$ components and of the dominance ratio are given in Table 9.

Finally, the additive and dominance components are also estimated and epistasis tested from the data of all

Table 7 Analyses of the $\mathrm{P}_{i}, \mathrm{~L}_{1 s i}$ and $\mathrm{L}_{2 s i}$ sets of families

\begin{tabular}{|c|c|c|c|c|c|c|}
\hline \multirow[b]{2}{*}{ Item } & \multicolumn{3}{|c|}{ With tester families } & \multicolumn{3}{|c|}{ Without tester families } \\
\hline & d.f. & MS & $P$ & d.f. & MS & $P$ \\
\hline \multicolumn{7}{|c|}{ Inbred lines as females } \\
\hline$†$ Epistasis & 4 & 0.18 & ns $\ddagger$ & 4 & 0.18 & ns \\
\hline Sums & 6 & 50.22 & $* * *$ & 4 & 26.10 & $* * *$ \\
\hline Differences & 6 & 11.76 & $* * *$ & 4 & 7.06 & $* * *$ \\
\hline \multicolumn{7}{|c|}{ Testers as females } \\
\hline Epistasis & 4 & 0.79 & ns & 4 & 0.79 & ns \\
\hline Sums & 6 & 53.29 & $* * *$ & 4 & 35.04 & $* * *$ \\
\hline Differences & 6 & 13.68 & $* * *$ & 4 & 10.04 & $* * *$ \\
\hline \multicolumn{7}{|c|}{ Combined analysis } \\
\hline Epistasis & 4 & 0.48 & ns & 4 & 0.48 & ns \\
\hline Sums & 6 & 70.00 & $* * *$ & 4 & 60.69 & $* * *$ \\
\hline Differences & 6 & 18.32 & $* * *$ & 4 & 16.84 & $* * *$ \\
\hline Interaction & 8 & 0.35 & $* * *$ & 8 & 0.35 & $* * *$ \\
\hline Error & 16512 & 0.09 & & 16512 & 0.09 & \\
\hline
\end{tabular}

† See Table 3 for comparisons.

†See Table 6 for probability.

Table 8 Analyses of the $\mathrm{P}_{i}, \mathrm{~L}_{1 \mathrm{~b} i}$ and $\mathrm{L}_{2 \mathrm{~b} i}$ sets of families

\begin{tabular}{|c|c|c|c|c|c|c|}
\hline \multirow[b]{2}{*}{ Item } & \multicolumn{3}{|c|}{ With tester families } & \multicolumn{3}{|c|}{ Without tester families } \\
\hline & d.f. & MS & $P$ & d.f. & MS & $P$ \\
\hline \multicolumn{7}{|c|}{ Inbred lines as females } \\
\hline$\dagger$ Epistasis & 4 & 1.14 & ns $\ddagger$ & 4 & 1.14 & ns \\
\hline Sums & 6 & 25.92 & $* * *$ & 4 & 21.86 & $* *$ \\
\hline Differences & 6 & 6.22 & ns & 4 & 4.43 & ns \\
\hline \multicolumn{7}{|c|}{ Testers as females } \\
\hline Epistasis & 4 & 4.22 & ns & 4 & 4.22 & ns \\
\hline Sums & 6 & 12.07 & $* *$ & 4 & 7.57 & ns \\
\hline Differences & 6 & 8.53 & $*$ & 4 & 6.02 & ns \\
\hline \multicolumn{7}{|c|}{ Combined analysis } \\
\hline Epistasis & 4 & 2.93 & ns & 4 & 2.93 & ns \\
\hline Sums & 6 & 18.95 & $* *$ & 4 & 27.23 & $* *$ \\
\hline Differences & 6 & 8.78 & $*$ & 4 & 8.44 & $*$ \\
\hline Interaction & 8 & 2.10 & $* * *$ & 8 & 2.10 & $* * *$ \\
\hline Error & 456 & 0.34 & & 456 & 0.34 & \\
\hline
\end{tabular}

†See Table 5 for comparisons.

‡See Table 6 for probability. 
Table 9 Estimates of the additive and dominance components of variation and of dominance ratio from various sources

\begin{tabular}{|c|c|c|c|c|c|c|}
\hline \multirow[b]{2}{*}{ Source } & \multicolumn{3}{|c|}{ With tester families } & \multicolumn{3}{|c|}{ Without tester families } \\
\hline & $\begin{array}{c}\text { Testers } \\
\text { as } \varnothing\end{array}$ & $\begin{array}{c}\text { Inbreds } \\
\text { as } q\end{array}$ & Combined & $\begin{array}{c}\text { Testers } \\
\text { as } \&\end{array}$ & $\begin{array}{c}\text { Inbreds } \\
\text { as } \varnothing\end{array}$ & Combined \\
\hline \multicolumn{7}{|l|}{$\sigma^{2}$ (additive) } \\
\hline Standard TTC & 34.70 & 31.63 & 34.57 & 22.67 & 30.22 & 26.36 \\
\hline Selfed fams & 24.94 & 26.47 & 22.47 & 12.88 & 17.35 & 15.09 \\
\hline Backcrosses & 11.91 & 4.99 & 5.44 & 9.88 & 2.74 & 6.28 \\
\hline \multicolumn{7}{|c|}{ Additive variance, $D^{\prime}$} \\
\hline Standard TTC & 138.80 & 126.52 & 138.28 & 90.68 & 120.88 & 105.44 \\
\hline Selfed fams & 99.76 & 105.88 & 89.88 & 51.52 & 69.40 & 60.36 \\
\hline Backcrosses & 107.19 & 179.64 & 87.04 & 88.92 & 98.64 & 100.48 \\
\hline \multicolumn{7}{|l|}{$\sigma^{2}$ (dominance) } \\
\hline Standard TTC & 23.32 & 23.75 & 30.69 & 17.16 & 17.88 & 17.68 \\
\hline Selfed fams & 5.71 & 6.67 & 5.80 & 3.36 & 4.85 & 4.12 \\
\hline Backcrosses & 2.06 & 3.22 & 2.15 & 1.17 & 1.96 & 1.59 \\
\hline \multicolumn{7}{|c|}{ Dominance variance, $H^{\prime}$} \\
\hline Standard TTC & 93.28 & 95.00 & 122.76 & 68.64 & 71.52 & 70.72 \\
\hline Selfed fams & 91.36 & 106.72 & 92.80 & 53.76 & 77.60 & 65.92 \\
\hline Backcrosses & 32.96 & 51.52 & 34.40 & 18.72 & 30.72 & 25.44 \\
\hline \multicolumn{7}{|c|}{ Dominance ratio, $\sqrt{H^{\prime} / D^{\prime}}$} \\
\hline Standard TTC & 0.82 & 0.87 & 0.94 & 0.87 & 0.77 & 0.82 \\
\hline Selfed fams & 0.96 & 1.00 & 1.01 & 1.02 & 1.06 & 1.05 \\
\hline Backcrosses & 0.55 & 0.54 & 0.63 & 0.46 & 0.56 & 0.50 \\
\hline
\end{tabular}

See text for definitions of $D^{\prime}$ and $H^{\prime}$.

the generations using the following comparisons where $\mathrm{L}_{1 i}^{\prime}$ etc. represent sums of reciprocals:

additive effects $=$ variance of

$$
\left(\mathrm{L}_{1 i}^{\prime}+\mathrm{L}_{2 i}^{\prime}+\mathrm{L}_{1 \mathrm{~s} i}^{\prime}+\mathrm{L}_{2 \mathrm{~s} i}^{\prime}+\mathrm{L}_{1 \mathrm{~b} i}^{\prime}+\mathrm{L}_{2 \mathrm{~b} i}^{\prime}\right) \quad\left(\sigma^{2}=\frac{1}{9} D^{\prime}\right)
$$

dominance effects $=$ variance of

$$
\left(\mathrm{L}_{1 i}^{\prime}-\mathrm{L}_{2 i}^{\prime}+\mathrm{L}_{1 \mathrm{~s} i}^{\prime}-\mathrm{L}_{2 \mathrm{~s} i}^{\prime}+\mathrm{L}_{1 \mathrm{~b} i}^{\prime}-\mathrm{L}_{2 \mathrm{~b} i}^{\prime}\right) \quad\left(\sigma^{2}=\frac{49}{576} H^{\prime}\right)
$$

epistasis $(1)=$ variance of

$$
\left(\mathrm{L}_{1 i}^{\prime}+\mathrm{L}_{2 i}^{\prime}-\mathrm{L}_{1 \mathrm{~s} i}^{\prime}-\mathrm{L}_{2 \mathrm{~s} i}^{\prime}-\mathrm{L}_{1 \mathrm{~b} i}^{\prime}-\mathrm{L}_{2 \mathrm{~b} i}^{\prime}\right)
$$

epistasis $(2)=$ variance of

$$
\left(\mathrm{L}_{1 \mathrm{~s} i}^{\prime}+\mathrm{L}_{2 \mathrm{~s} i}^{\prime}-\mathrm{L}_{1 \mathrm{~b} i}^{\prime}-\mathrm{L}_{2 \mathrm{~b} i}^{\prime}\right)
$$

epistasis $(3)=$ variance of

$$
\left(\mathrm{L}_{1 i}^{\prime}-\mathrm{L}_{2 i}^{\prime}+2 \mathrm{~L}_{1 \mathrm{~s} i}^{\prime}-2 \mathrm{~L}_{2 \mathrm{~s} i}^{\prime}-3 \mathrm{~L}_{1 \mathrm{~b} i}^{\prime}+3 \mathrm{~L}_{2 \mathrm{~b} i}^{\prime}\right) \text {. }
$$

Each of these variances is tested against an error MS which is calculated by the appropriate manipulation of various interaction MSs. The results obtained are as follows:

additive effects

$D^{\prime}=129.54$

dominance effects

$H^{\prime}=70.25$

dominance ratio

$$
\sqrt{H^{\prime} / D^{\prime}}=0.74
$$

epistasis (1)

epistasis (2)

$F(4,24)=4.56(P \leqslant 0.01)$;

$F(4,16)=3.65(P \leqslant 0.05)$;

epistasis (3)

\section{Discussion and conclusion}

An important conclusion from the theoretical analysis is that the standard comparisons of $\mathrm{L}_{1 i}, \mathrm{~L}_{2 i}$ and $\mathrm{L}_{3 i}$ families do not provide unbiased tests of the additive, dominance and epistatic components unless the family scores are averaged over reciprocals. Furthermore, both dominance and epistatic components are biased by the additive variance but the magnitude of this bias is expected to be rather small except when the additive variance is exceptionally large. The largest bias, on the other hand, is incurred by the additive variance whose magnitude is also expected to vary considerably with the direction and magnitude of the $h_{a 1}$ and $h_{a 2}$ types of dominance effect.

Similar biases will also be incurred by the sums component of the backcross families when the analysis involves only one set of reciprocals. The magnitude of this bias, however, is reduced considerably when testers are used as mothers and the two types of dominance effects take the same sign. Tests of dominance and epistasis, on the other hand, are not biased and they provide unambiguous estimates of these effects, like those based on the selfed families. 
A general conclusion from the analyses of different sets of families is that epistasis is not involved in the genetic control of amylose content. Out of the nine tests, only one test from the standard TTC detects nonallelic interaction (Table 6) and even this test can be ignored as it is likely to be biased by the additive genetic variance which takes a comparatively large value in the present case. While these results support Pooni et al. (1993b), comparisons involving the standard, selfed and backcross families, on the other hand, detect epistasis with such a consistency (see Materials and analyses for tests) that one is compelled to conclude that epistasis is an important component of the genetic control of this trait (also see Pooni et al., 1993a). These seemingly contradictory results, however, may have occurred partly because of an increased statistical efficiency of the latter tests and partly because the two types of tests may be detecting different types of epistasis.

The additive and dominance effects, on the other hand, are detected consistently by the analysis of the standard and the selfed families suggesting that they are the most important components of the genetic variation displayed by amylose content. The same tests, however, are either non-significant or marginally significant for the backcross families, particularly where testers are used as female parents as the tests are highly insensitive in this case. These differences are attributable to the expectations of the $\sigma^{2} \mathrm{~s}$ which differ considerably between the various types of families (see Table 9).

Comparisons of the $\sigma^{2}$ values further reveal that the additive component is always larger than the dominance component indicating that either $h_{\mathrm{a} 1}$ and $h_{\mathrm{a} 2}$ oppose each other or their sum is, on average, less than $2 d_{\mathrm{a}}$. While the $h_{\mathrm{a} 1}$ and $h_{\mathrm{a} 2}$ types of non-additive effects can not be separated when alleles are dispersed in the testers, in the present case, however, we can approximate $H_{1}^{\prime}$ and $H_{2}^{\prime}$ with $\frac{64}{9} \sigma^{2}\left(\mathrm{~L}_{1 i}-\mathrm{RL}_{2 i}\right)$ and $\frac{64}{9} \sigma^{2}$ $\left(\mathrm{RL}_{1 i}-\mathrm{L}_{2 i}\right)$, respectively, where $\mathrm{RL}_{1 i}$ etc. represent families whose seed are produced using the testers as females. The corresponding sums of these comparisons, $\mathrm{L}_{1 i}+\mathrm{RL}_{2 i}$ and $\mathrm{RL}_{1 i}+\mathrm{L}_{2 i}$, also provide unbiased tests of the additive genetic variance and the respective $\sigma^{2}$ s have the expectation of $\frac{19}{144} D^{\prime}$. These analyses show that dominance does indeed differ with gene dosage and $\sqrt{H_{1}^{\prime} / D^{\prime}}$ takes a smaller value $(0.75)$ than $\sqrt{H_{2}^{\prime} / \mathrm{D}^{\prime}}\left(0.91\right.$, and $H_{1}^{\prime}=53.65, H_{2}^{\prime}=79.57$ and $D^{\prime}=94.46$ ).

Finally, the impact of excluding extreme genotypes from the sample is clearly apparent from the estimates of the additive and dominance components which show marked decreases in their magnitudes (see Table 9). However, these changes have had a marginal effect on the dominance ratio because dominance is high for the trait under investigation.

\section{References}

GALE, M. D. 1976. High alpha-amylase breeding and genetical aspects of the problem. Cereal Res. Comm., 4, 231-243.

JINKS, J. L. AND PERKINS, J. M. 1970. A general method for the detection of additive, dominance and epistatic components of variation. III. $F_{2}$ and backcross populations. Heredity, 25, 419-429.

JiNKS, J. L., PERKINS, J. M. AND BREESE, E. L. 1969. A general method of detecting additive, dominance and epistatic variation for metrical traits. II. Application to inbred lines. Heredity, 24, 45-57.

JULIANO, B. o. 1971. A simplified assay for milled rice amylose. Cereal Sci. Today, 16, 334-338.

KEARSEY, M. J. AND JINKS, J. L. 1968. A general method of detecting additive, dominance and epistatic variation for metrical traits. I. Theory. Heredity, 23, 403-409.

POONI, H. S. AND JINKS, J. L. 1979. Sources and biases of the predictors of the properties of recombinant inbreds produced by single seed descent. Heredity, 42, 41-48.

POONI, H. S., JINKS, J. L. AND POONI, G. S. 1980. A general method for the detection and estimation of additive, dominance and epistatic variation for metrical traits. IV. Triple test cross analysis for normal families and their selfs. Heredity, 44, 177-192.

POONI, H. S., KUMAR, I. AND KHUSH, G. S. 1992. A comprehensive model for disomically inherited metrical traits expressed in triploid tissues. Heredity, 69, 166-174.

POONI, H. S., KUMAR, I. AND KHUSH, G. S. 1993a. Genetical control of amylose content in selected crosses of indica rice. Heredity, 70, 269-280.

POONI, H. S., KUMAR, I. AND KHUSH, G. S. 1993b. Genetical control of amylose content in a diallel set of rice crosses. Heredity, 71, 603-613.

SNAPE, J. W., LAW, C. N. AND WORLAND, A. J. 1975. A method for the detection of epistasis in chromosome substitution lines of hexaploid wheat. Heredity, 34; 297-303.

VIRK, D. S. AND JINKS, J. L. 1977. The consequences of using inadequate testers in a simplified triple test cross. Heredity, 38, 237-251. 